\title{
A PARTICIPAÇÃO NO FECHAMENTO DE MINA NO DIREITO COMPARADO
}

\author{
José Cláudio Junqueira Ribeiro \\ Possui Graduação em Engenharia Civil pela Universidade Federal de Minas Gerais (1973), \\ Especialização em Engenharia Sanitária pela Escola de Engenharia da UFMG (1974), \\ Mestrado em Genie Sanitaire Et Urbanisme pela Ecole Nationale de La Sante Publique, \\ Rennes, França (1977) e Doutorado em Saneamento, Meio Ambiente e Recursos Hídricos \\ pela Universidade Federal de Minas Gerais (2005). Atualmente é Professor titular de Gestão \\ Ambiental da Faculdade de Engenharia e Arquitetura da Universidade Fumec e Professor da \\ disciplina Impactos Ambientais, do Mestrado em Direito Ambiental da Escola Superior Dom \\ Helder Câmara. Foi Pesquisador Pleno da Fundação Estadual do Meio Ambiente de MG e seu \\ Presidente por três mandatos, quando se aposentou. Consultor com grande experiência, atuan- \\ do principalmente nas seguintes áreas: Sistema de Gestão Ambiental, Avaliação de Impacto, \\ Licenciamento, Normalização, Resíduos Sólidos Urbanos RSU, \\ de Serviço de Saúdẽ RSS, e Eletroeletrônicos REEE e Indicadores Ambientais, \\ de Produção mais Limpa e de Desempenho Ambiental. \\ End. eletrônico: jcjunqueira@yahoo.com
}

\section{Samuel Felisbino Mendes}

\begin{abstract}
Mestre em Direito Ambiental e Sustentabilidade pela Escola Superior Dom Helder Câmara (2013). Bolsista da FAPEMIG (2012-2013). Pós-Graduado em Direito Ambiental pela Universidade Gama Filho (2012). Graduação em Direito pela Universidade Federal de Minas Gerais (2005). Advogado ambiental, com oito anos de experiência em consultoria de legislação ambiental, de saúde ocupacional e segurança do trabalho. Tem experiência na área de Direito, com ênfase em Direito Ambiental.

End. eletrônico: sam.mendes@gmail.com
\end{abstract}

\section{RESUMO}

A participação da sociedade civil no fechamento de minas é crucial para a garantia de uma sustentabilidade abrangente, que contemple as diferentes visões acerca da efetivação do direito ao meio ambiente ecologicamente equilibrado. Este trabalho, a partir de uma pesquisa bibliográfica e documental, tem como objetivo identificar e analisar a legislação brasileira sobre fechamento de mina, avaliando os mecanismos de participação popular nesse processo, comparando-os com as formas de participação durante o processo de licenciamento ambiental e com as normas de outros países com liderança global na atividade minerária. O licenciamento ambiental já prevê a participação das comunidades afetadas por empreendimentos geradores de significativo impacto ambiental, por meio de audiências públicas. Entretanto, no caso da mineração, verificou-se que esses instrumentos não 
têm sido suficientes para garantir a sustentabilidade após o fechamento das minas, havendo necessidade de novos ordenamentos jurídicos complementares, como demonstram as experiências nacional e internacional.

Palavras-chave: Licenciamento ambiental. Fechamento de mina. Princípio da Participação. Desenvolvimento sustentável. Sustentabilidade no pós-mina.

\title{
MINE CLOSURE PARTICIPATION IN COMPARATIVE LAW
}

\begin{abstract}
The civil society participation in mine closure is crucial to guarantee a broad sustainability, one that considers the different approaches on the right to a healthy environment. This work, from a bibliographic and documental research, intends to identify and analyze the mine closure Brazilian legislation, assessing the mechanisms of popular participation in this process, comparing them with the forms of participation in the environmental licensing process and with international legislation from other countries with global leadership in mining activity. The public hearing process is already present in the environmental licensing to grant the participation of communities affected by projects generating significant environmental impact. Nonetheless, as concluded in this study, this instrument has not been successful enough in mining activities, especially concerning sustainability in mine closure. For this reason, as shown by the national and international experience, new rules are necessary to grant the participation of affected communities.
\end{abstract}

Keywords: Environmental Licensing. Mine Closure. Participation Principle. Sustainable Development. Post Closure Sustainability. 


\section{INTRODUÇÃO}

No texto constitucional brasileiro em vigor, o meio ambiente é protegido como um direito e também como um dever estatal e da coletividade. Para atingir o objetivo de proteção ambiental, dentre as várias incumbências mínimas do Poder Público na efetivação do direito constitucional ao meio ambiente, a Constituição brasileira prevê a realização de estudos de impacto ambiental, prévios e públicos. No mesmo sentido, em regulamentação a esta matéria, a Lei n. 6.938 de 31 de agosto de 1981, a chamada Política Nacional do Meio Ambiente, estabeleceu vários instrumentos de comando e controle e instrumentos de planejamento, visando a efetivar o direito ao meio ambiente ecologicamente equilibrado.

Entretanto, como frequentemente ocorre nos momentos iniciais de implantação de políticas públicas, os instrumentos de comando e controle foram os mais utilizados, pois apresentam caráter de afirmação fortemente acentuado, quando o administrador expressa seu comando por meio de atos autorizativos e exercita o seu controle por meio de atividades de fiscalização e penalidades.

Assim, dentro da Política Nacional de Meio Ambiente brasileira, o licenciamento ambiental foi o instrumento prioritário desde a década de 1980, inclusive com a inovação de um sistema trifásico, composto por Licença Prévia (LP), Licença de Instalação (LI) e Licença de Operação (LO). Esse sistema foi instituído pelo Decreto n. 88.351, de 01 de junho de 1983, aumentando a complexidade do sistema bifásico - Licença de Instalação e Licença de Funcionamento - inaugurado no precursor sistema norte-americano National Environmental Protection Act (NEPA) e que, desde o final dos anos de 1970, foi adotado por alguns estados brasileiros, como São Paulo, Rio de Janeiro e Minas Gerais.

Com a edição da Resolução CONAMA 01/86, definiu-se o conceito de impacto ambiental no ordenamento brasileiro, estabelecendo-se as diretrizes para a elaboração dos estudos de impacto ambiental e respectivo relatório, os chamados EIA/RIMA.

No caso da mineração, atividade de grande importância na economia nacional, com destaque para o estado de Minas Gerais, verificou-se, ao longo do tempo, a partir dos impactos gerados antes, durante e pós-mina, que a efetivação do direito ao meio ambiente ecologicamente equilibrado é um processo conflituoso, considerando as diferentes visões e discursos em torno da noção de desenvolvimento sustentável. Tais concepções decorrem 
dos diferentes sujeitos envolvidos no processo de efetivação desse direito, podendo atuar no seu fortalecimento ou limitação.

A existência de várias minas, em atividade ou exauridas, anteriores à aprovação do marco legal brasileiro, exigiu a prática de procedimento corretivo, com prazos extensos, muitas vezes prorrogados, sem a participação popular, sobretudo das populações diretamente afetadas por esses empreendimentos geradores de significativo impacto ambiental.

No processo de licenciamento ambiental de novos empreendimentos minerários, há a previsão legal de estudos ambientais com identificação e quantificação dos impactos positivos e negativos, e para estes, medidas mitigadoras e compensatórias. Nestes processos, em tese, a população afetada passou a encontrar mecanismos institucionais para a exposição de suas visões e demandas, seja através da apreciação dos processos de licenciamento por órgãos colegiados com representação dos diversos segmentos da sociedade, seja através da participação direta em processos de audiência pública.

Entretanto, as análises prospectivas dos impactos decorrentes após o término da exploração mineral ainda são pouco desenvolvidas em nosso país, fato que merece bastante atenção e estudo, já que, neste momento, podem ocorrer restrições de uso e ocupação do solo e consequentemente mudanças na vocação das áreas, com reflexos significativos em aspectos como trabalho, renda, produção, que impactam diretamente o desenvolvimento socioeconômico local.

O presente trabalho pretende identificar e analisar a legislação brasileira sobre o licenciamento ambiental da atividade minerária, com destaque para avaliar se a existência de mecanismos de participação popular nesse processo seria suficiente para garantir a sustentabilidade, em especial considerando o pós-fechamento da mina.

Pretende-se também comparar as disposições legais brasileiras sobre o tema com aquelas existentes em outros países com liderança global na atividade minerária, de maneira a avaliar possíveis méritos da legislação nacional, bem como possibilidades de avanços para garantir uma maior participação das pessoas afetadas pelo encerramento dos empreendimentos minerários.

Dessa forma, na seção seguinte analisa-se o licenciamento ambiental e sua importância para a sustentabilidade da atividade minerária, relacionando esse instrumento ao fechamento de minas. Na terceira seção procede-se a uma análise do fechamento de minas no Direito brasileiro, 
analisando as suas prescrições normativas e os possíveis mecanismos de participação nesse processo. Já na quarta seção analisa-se o fechamento de mina no Direito comparado a partir de uma revisão da literatura internacional sobre o tema. Por fim, na quinta seção compara-se a normativa brasileira de fechamento de minas com as normativas existentes em outros países, avaliando seus pontos positivos e negativos.

\section{O LICENCIAMENTO AMBIENTAL E O FECHAMENTO DE MINAS}

Como se sabe, a mineração "constitui uma das atividades que mais causa impacto ao meio ambiente" , por ser altamente dependente dos recursos naturais. Essa atividade extrativista impacta várias áreas com diversos graus de alteração, tanto dos fatores bióticos quanto abióticos, além de produzir interferências diversas nos meios social e econômico. Esse caráter potencialmente degradador das atividades minerárias é reconhecido no próprio texto constitucional brasileiro, que prevê a obrigação de recuperação, vinculada ao direito ao meio ambiente sadio, previsto no caput do Artigo 225:

Art. 225

$[\ldots]$

$\S 2^{\circ}$ Aquele que explorar recursos minerais fica obrigado a recuperar o meio ambiente degradado, de acordo com solução técnica exigida pelo órgão público competente, na forma da lei.

Por outro lado, a mineração também pode ser considerada uma atividade propulsora do desenvolvimento, de interesse nacional, de utilidade pública e que pode, inclusive, desempenhar importante função ambiental. Por esse motivo, se faz necessário regular essa atividade econômica, no sentido de possibilitar conciliar o desenvolvimento com a proteção ambiental, nos moldes previstos no texto constitucional:

Art. 170 - A ordem econômica, fundada na valorização do trabalho humano e na livre iniciativa, tem por fim assegurar a todos existência digna, conforme os ditames da justiça social, observados os seguintes princípios:

${ }^{1}$ FREITAS, 2001, p. 186. 


\section{$[\ldots]$}

VI - defesa do meio ambiente, inclusive mediante tratamento diferenciado conforme o impacto ambiental dos produtos e serviços e de seus processos de elaboração e prestação².

Essa conciliação inclusive se coaduna com o Princípio da Sustentabilidade, tão caro ao atual contexto de crise socioambiental, conforme inicialmente previsto no Princípio 4 da Declaração do Rio sobre Meio Ambiente e Desenvolvimento:

\section{Princípio 4}

Para se alcançar um desenvolvimento sustentável, a proteção ambiental deve constituir parte integrante do processo de desenvolvimento e não pode ser considerada separadamente ${ }^{3}$. (grifo nosso)

E conforme o compromisso renovado pelas nações na Declaração da Rio+20 sobre O Futuro que Queremos:

Nós, os Chefes de Estado e de Governo e representantes de alto nível, reunidos no Rio de Janeiro, Brasil, de 20 a 22 de junho de 2012, com plena participação da sociedade civil, renovamos o nosso compromisso com o desenvolvimento sustentável, e para assegurar a promoção de um futuro economicamente, socialmente e ambientalmente sustentável para o nosso planeta e para as gerações presentes e futuras $^{4}$. (tradução e grifo nosso) $)^{5}$

Conforme opina Freire, dependente dos recursos minerais", necessário se faz regulamentar juridicamente o seu exercício. Logo, a atividade de exploração mineral foi considerada como potencialmente poluidora e utilizadora de recursos ambientais pela legislação brasileira, conforme o Anexo VIII da Lei 6.938 de 31 de agosto de 1981, que dispõe sobre a Política Nacional do Meio Ambiente.

\footnotetext{
${ }^{2}$ BRASIL, 1988.

${ }^{3}$ ORGANIZAÇÃO DAS NAÇÕES UNIDAS, 1992.

${ }^{4}$ ORGANIZAÇÃO DAS NAÇÕES UNIDAS, 2012.

${ }^{5}$ We, the heads of State and Government and high level representatives, having met at Rio de Janeiro, Brazil, from 20-22 June 2012, with full participation of civil society, renew our commitment to sustainable development, and to ensure the promotion of economically, socially and environmentally sustainable future for our planet and for present and future generations.
}

${ }^{6}$ FREIRE, 2010, p. 60. 
Como consequência dessa classificação, a mineração foi enquadrada, nas Resoluções CONAMA 01, de 23 de janeiro de 1986, e 237, de 19 de dezembro de 1997, entre as atividades que dependem de prévio estudo de impacto ambiental e licenciamento do órgão ambiental competente, sem prejuízo de outras licenças legalmente exigíveis. Esse licenciamento ambiental é um dos instrumentos importantes na regulamentação jurídica da atividade de mineração ${ }^{7}$.

Dado o alto grau de externalidades das atividades minerárias, que, mesmo no pós-mina, continuam existindo, já que são inerentes ao processo de mineração, seu licenciamento ambiental também tem especificidades comuns às atividades causadoras de grandes impactos, sobretudo a elaboração de estudos de impacto ambiental e respectivo relatório de impacto ambiental (EIA/RIMA), a serem submetidos à aprovação do órgão ambiental competente, nos termos das normativas legais sobre o tema. Essas externalidades.

A mineração contribui sobremaneira para a degradação das áreas pela movimentação de grandes volumes de terra, suprimindo a vegetação, afugentando a fauna, modificando a topografia e destruindo a paisagem. Depois de exauridas as minas, sobram as cavas, grandes depressões no terreno de onde os bens minerais são extraídos, as pilhas de estéril, montes de material desagregado das camadas mais superficiais que não apresentam concentração mineral de interesse econômico, e as barragens de rejeito, grandes estruturas para fins de contenção ou acumulação dos rejeitos resultantes da lavagem e beneficiamento do minério.

Segundo Regensburger, Comin e Aumond ${ }^{8}$, tal atividade pode gerar impactos no solo, que alteram sua composição química e muitas de suas características essenciais, podendo afetar a fertilidade do solo ou deixá-lo pobre em nutrientes. Por exemplo, apenas em Minas Gerais existem cerca de 600 barragens de rejeitos da atividade minerária, que representam potencial impacto ao assoreamento e contaminação dos cursos de água, danos à fauna e flora e à segurança das populações.

Outro aspecto que merece destaque no âmbito da regulamentação da atividade minerária é o processo de fechamento das minas, que abrange toda a sua vida, desde a fase dos estudos de viabilidade econômica até o encerramento da atividade minerária, incluindo o descomissionamento, a

${ }^{7}$ FREIRE, 2010, p. 113.

${ }^{8}$ REGENSBURGER; COMIN; AUMOND, 2008. 
reabilitação e o uso futuro da área impactada.

Inicialmente, para o pós-mina, a norma brasileira estabeleceu a obrigatoriedade do Plano de Recuperação de Área Degrada (PRAD), nos termos do Decreto n. 97.632, de 10 de abril de 1989, regulamentado o artigo $2^{\circ}$, inciso VIII, da Lei n. 6.938 de 31 de agosto de 1981, e que dispunha:

Artigo $1^{\circ}$ - Os empreendimentos que se destinam à exploração de recursos minerais deverão, quando da apresentação do Estudo de Impacto Ambiental - EIA e do Relatório de Impacto Ambiental - RIMA, submeter à aprovação do órgão ambiental competente, plano de recuperação de área degradada.

Parágrafo Único - Para os empreendimentos já existentes, deverá será apresentado ao órgão ambiental competente, no prazo máximo de 180 (cento e oitenta) dias, a partir da data de publicação deste Decreto, um plano de recuperação da área degradada. Artigo $2^{\circ}$ - Para efeito deste Decreto são considerados como degradação os processos resultantes dos danos ao meio ambiente, pelo quais se perdem ou se reduzem algumas de suas propriedades, tais como, a qualidade ou capacidade produtiva dos recursos ambientais.

Artigo $3^{\circ}$ - A recuperação deverá ter por objetivo o retorno do sítio degradado a uma forma de utilização, de acordo com um plano preestabelecido para o uso do solo, visando à obtenção de uma estabilidade do meio ambiente.

Artigo $4^{\circ}$ - Este Decreto entra em vigor na data de sua publicação.

Artigo $5^{\circ}$ - Revogam-se as disposições em contrário .

Os efeitos produzidos por essa norma legal foram milhares de planos enviados aos órgãos ambientais, que em sua maioria, se limitavam à previsão de medidas relacionadas à estabilidade dos terrenos com taludes, adubação verde e revegetação com espécies, nem sempre do bioma original. A falta de capacidade dos órgãos ambientais para a análise, e a prioridade dada a novos processos de licenciamento ambiental, condenou tais Planos de Recuperação, em grande parte, às prateleiras.

Observa-se que o entendimento geral foi garantir a estabilidade física e revegetar, como se esta fosse a única alternativa de uso do solo para a estabilidade do meio ambiente. Outros elementos, como a topografia para recomposição da paisagem, estrutura socioeconômica e aspectos culturais, foram relegados ao segundo plano. Mesmo do ponto de vista biótico, as

${ }^{9}$ BRASIL, 1989. 
soluções apresentadas deixaram a desejar, pois não houve maiores compromissos com os biomas originais.

Por esse motivo, verificou-se a necessidade de regulamentação complementar, além do então previsto no licenciamento ambiental e na obrigação dos $\mathrm{PRAD}$, principalmente no que se refere à participação das comunidades envolvidas sobre o uso futuro das áreas degradadas.

Observa-se que as normas legais que tratam de maneira específica o tema, prevendo inclusive obrigações e instrumentos de maior vigor, são relativamente recentes. Inclusive no plano internacional a preocupação com o tema também não é tão antiga, conforme dispõem Macdonald, McGuire e Weston ${ }^{10}$ em sua análise da literatura internacional. Inclusive, a doutrina brasileira aponta que o Fechamento de Minas obteve maior importância mundialmente a partir da realização na Espanha, em setembro de 2000, das I Jornadas Ibero Americanas sobre Cierre de Minas ${ }^{11}$.

$\mathrm{O}$ fechamento de mina deve ser planejado desde a concepção do empreendimento, visando, sobretudo, garantir que no pós-mina os impactos ambientais, sociais e econômicos sejam mitigados e que a área impactada tenha condições seguras e estáveis, a partir das melhores técnicas de controle e monitoramento. Outro elemento importante é proporcionar à área impactada um uso futuro que respeite os aspectos socioambientais e econômicos da área de influência do empreendimento, além de garantir que o ônus da recuperação ambiental do sítio não recairá sobre o poder público, caso ocorra insolvência financeira do projeto, antes do término da sua vida útil planejada12.

A preocupação com o fechamento de minas não tem viés exclusivamente ambiental, não devendo contemplar exclusivamente os aspectos de estabilidade física e de vegetação. Tampouco necessariamente tem o sentido de recuperação da área degradada pela mineração à condição existente antes da realização da atividade. Até porque a recuperação será sempre parcial e compensatória, já que tecnicamente é praticamente impossível retornar o ambiente ao seu exato estado anterior.

Nesse sentido, a Lei n. 9.985, de 18 de julho de 2000, que dispõe sobre o Sistema Nacional de Unidades de Conservação - SNUC - define em seu Artigo $2^{\circ}$ :

\footnotetext{
$\overline{{ }^{10} \text { MACDONALD; MCGUIRE; WESTON, 2006, p. } 3 .}$

${ }^{11}$ POVEDA, 2007, p. 130

${ }^{12}$ FLORES, 2006, p. 65.
} 
Art. $2^{\circ}$ - Para os fins previstos nesta Lei, entende-se por:

$[\ldots]$

XIII - recuperação: restituição de um ecossistema ou de uma população silvestre degradada a uma condição não degradada, que pode ser diferente de sua condição original;

XIV - restauração: restituição de um ecossistema ou de uma população silvestre degradada o mais próximo possível da sua condição original $[\ldots]^{13}$ (grifo nosso)

Dessa forma, a recuperação da área não visa primordialmente fazer com que a área volte ao que era antes, mas torná-la apta para algum novo uso. Mesmo para a restauração, a própria previsão legal admite aproximações, ao mencionar uma restituição mais próxima do possivel considerando a condição original.

A análise do uso futuro da área impactada pela mineração necessariamente obriga a consideração não apenas dos aspectos físicos e bióticos, mas também dos socioeconômicos da região onde se encontra inserida, de forma a levar em conta o bem-estar individual e coletivo daqueles que futuramente serão afetados por este uso. Portanto, a regulamentação sobre fechamento de minas não pode se restringir apenas ao meio ambiente natural e à prevenção de formação de passivo ambiental, assegurando a recuperação ambiental do sítio de forma sistêmica e holística, não fragmentada, e integrada ao licenciamento do projeto de mineração.

A alternativa para conciliar a execução da atividade minerária com o desenvolvimento sustentável pressupõe também garantir que o projeto contribua para o desenvolvimento socioeconômico local, mesmo quando do seu fechamento, considerando as aptidões e vocações das áreas, os desejos das comunidades afetadas e as características regionais. Sobre essa ampliação do escopo do planejamento do fechamento de empreendimentos minerários, analisa-se o que dispõe o International Council on Mining and Metals ${ }^{14}(\mathrm{ICMM})$, que, inclusive, dispõe sobre a evolução da visão empresarial acerca do tema:

No passado, o planejamento do fechamento era obrigação da administração dos empreendimentos e focada em aspectos ambientais, com o envolvimento da comunidade, muitas vezes limitado a processos de consulta superficial. Hoje, no entanto, cada vez mais, os administradores consideram a participação da comunidade nos

\footnotetext{
${ }^{13}$ BRASIL, 2000.

${ }^{14}$ INTERNATIONAL COUNCIL ON MINING AND METALS, 2008, p. 4.
} 
objetivos pós-encerramento como a fonte de energia que vai permitir que as iniciativas de encerramento prosperem quando a mineradora não estiver mais envolvida. Para isso, o engajamento da comunidade é necessário na definição do escopo do desafio, na conceituação da solução, na implementação do projeto e na verificação dos resultados. Além de aumentar o nível de credibilidade, isso estabelece parcerias para impulsionar o sucesso e, ao fazê-lo, cria um fórum de transparência.

Fundamental para essa abordagem é a necessidade de considerar o fechamento como uma parte essencial do nosso negócio. A integração de considerações de encerramento no planejamento de uma operação e processos de engenharia é um importante mecanismo para uma mina criar um valor duradouro. (tradução nossa) $)^{15}$

\title{
3 O FECHAMENTO DE MINA NO DIREITO BRASILEIRO
}

\begin{abstract}
O Brasil regulamentou o fechamento de mina em diversas normas, prevendo também mecanismos de participação nesses processos. Primeiramente analisam-se as previsões normativas sobre o tema, para, em seguida, destacar a forma de participação prevista nesse processo.
\end{abstract}

\subsection{Disposições normativas}

Conforme já mencionado, a recuperação de áreas degradadas por empreendimentos minerários mereceu dispositivo constitucional específico, dada a relevância da matéria em comento:

Art. 225

[...]

$\S 2^{\circ}$ - Aquele que explorar recursos minerais fica obrigado a recuperar o meio ambiente degradado, de acordo com solução técnica exigida pelo órgão público competente, na forma da lei. ${ }^{16}$

\footnotetext{
${ }^{15}$ In the past, closure planning has been the responsibility of operation management and focused on environmental aspects, with community involvement often limited to cursory consultation processes. Increasingly today, however, management looks to community ownership of the post closure goals as the well of energy that will permit closure initiatives to prosper when the mining company is no longer involved. To achieve this, community engagement is needed when scoping the challenge, conceptualizing the solution, implementing the design and verifying the outcomes. In addition to increasing the level of credibility, this establishes partnerships to drive success and, in doing so, creates a forum for transparency.

Fundamental to this approach is the need to consider closure as a core part of our business. The integration of closure considerations into an operation's planning and engineering processes is an important mechanism for a mine to create lasting value.
}

${ }^{16}$ BRASIL, 1988. 
Pela redação do dispositivo constitucional, é possível perceber que a recuperação de áreas é obrigação dos empreendedores que exploram recursos minerais. Essa recuperação será exigida e fiscalizada pelo órgão competente, ou seja, o órgão ambiental licenciador, tendo em vista que tal atividade estaria incluída na competência da fiscalização e controle, nos termos previsto no $\S 2^{\circ}$ do Art. 11 da Lei n. 6.938/81, em interpretação conjugada com o Art. 10 da mesma lei.

Vale lembrar que a recuperação de áreas degradadas é também um dos princípios da Política Nacional do Meio Ambiente, nos termos do Art. $2^{\circ}$, VIII, da Lei n. 6.938/81, bem como um de seus objetivos, previsto no Art. $4^{\circ}$, VII:

Art. $2^{\circ}$ - A Política Nacional do Meio Ambiente tem por objetivo a preservação, melhoria e recuperação da qualidade ambiental propícia à vida, visando assegurar, no País, condições ao desenvolvimento sócio-econômico, aos interesses da segurança nacional e à proteção da dignidade da vida humana, atendidos os seguintes princípios:

$[\ldots]$

VIII - recuperação de áreas degradadas;

$[\ldots]$

Art. $4^{\circ}$ - A Política Nacional do Meio Ambiente visará:

$[\ldots]$

VII - à imposição, ao poluidor e ao predador, da obrigação de recuperar e/ou indenizar os danos causados e, ao usuário, da contribuição pela utilização de recursos ambientais com fins econômicos. ${ }^{17}$ (grifos nossos)

Tal obrigação foi regulamentada pelo Decreto n. 97.632, de 10 de abril de 1989, que exigiu a apresentação de um plano de recuperação de áreas degradadas a ser analisado e aprovado pelo órgão ambiental competente. Dessa forma, embora o comando constitucional determine que a solução técnica de recuperação de áreas degradadas seja aquela exigida pelo órgão competente, a regulamentação permite ao empreendedor propor as medidas de recuperação que serão adotadas, sendo tais medidas posteriormente analisadas e aprovadas e/ou rejeitadas pelo órgão ambiental. Esta possibilidade se coaduna com outros princípios também de sede constitucional, quais sejam o Princípio da Eficiência (Art. 37) e os Princípios

${ }^{17}$ BRASIL, 1981. 
Gerais da Atividade Econômica (Art. 170), sobretudo o livre exercício das atividades econômicas e o já mencionado Princípio da Defesa do Meio Ambiente.

Apesar de entendimentos divergentes na doutrina, ao permitir que o próprio minerador proponha as medidas de recuperação a serem realizadas, o agente ambiental conta, de antemão, com a adesão do empreendedor à execução de tais medidas, sob pena de posterior penalização. Além disso, obedecendo aos princípios do desenvolvimento sustentável, também de sede constitucional, no planejamento da recuperação das áreas degradadas, o empreendedor poderá considerar as medidas mais eficientes do ponto de vista ambiental, bem como aquelas mais exequíveis do ponto de vista econômico e tecnológico.

Além dessa solução aberta, prevista na normativa federal, outras normas legais merecem comento. Primeiramente menciona-se a NRM-21, ou Norma Reguladora da Mineração n. 21, aprovada pela Portaria DNPM 237 , de 18 de outubro de 2001. De antemão, vale lembrar que, considerando o interesse social no aproveitamento racional dos bens minerais e a minimização dos impactos ambientais decorrentes da atividade minerária, o Departamento Nacional de Produção Mineral (DNPM), nos termos do Art. $2^{\circ}$, inciso VII, do Anexo I do Decreto n. 7.092/10, pode, em caráter complementar, editar normas e exercer a fiscalização sobre o controle ambiental das atividades de mineração, atuando em articulação com os demais órgãos responsáveis.

Assim, a NRM-21, aprovada pelo DNPM, define procedimentos administrativos e operacionais em caso de reabilitação de áreas pesquisadas, mineradas e impactadas. Essa norma traz novas definições acerca do que seriam áreas pesquisadas, mineradas e impactadas:

21.2.1 Entende-se por área pesquisada para efeito desta Norma, toda área utilizada pela atividade de pesquisa geológica.

21.2.2 Entende-se por área minerada para efeito desta Norma, toda área utilizada pela atividade mineira, seja a área da própria mina, as áreas de estocagem de estéril, minérios e rejeitos, de vias de acesso e demais áreas de servidão.

21.2.3 Entende-se por área impactada para efeito desta Norma, toda área com diversos graus de alteração tanto dos fatores bióticos quanto abióticos causados pela atividade de mineração. ${ }^{18}$ (grifos nossos)

${ }^{18}$ DEPARTAMENTO NACIONAL DE PRODUÇÃO MINERAL, 2001. 
Tais diferenciações fazem sentido apenas considerando-se as particularidades do empreendimento minerário ${ }^{19}$, uma vez que, nos termos da norma, sejam as áreas consideradas pesquisadas, mineradas e/ou impactadas, estas deverão ser reabilitadas.

A NRM-21 exige a elaboração, por técnicos legalmente habilitados, de projetos de reabilitação que deverão ser previamente submetidos à avaliação do Departamento Nacional de Produção Mineral (DNPM) para aprovação. Define ainda, em 21.5, os itens mínimos que deverão estar contidos em tais projetos:

21.5 No projeto de reabilitação de áreas pesquisadas, mineradas e impactadas deve constar no mínimo os seguintes itens:

a) identificação e análise dos impactos ambientais diretos ou indiretos sobre os meios físico, biótico e antrópico;

b) aspectos sobre as conformações paisagística e topográfica, observando-se:

I- estabilidade;

II- controle de erosão;

III- drenagem;

IV- adequação paisagística e topográfica e

V- revegetação;

c) programa de acompanhamento e monitoramento;

d) planta atualizada na qual conste a situação topográfica atual das áreas a serem reabilitadas;

e) aptidão e uso futuro da área;

f) apresentar mapas, fotografias, planilhas e referências bibliográficas; e

g) cronograma físico e financeiro do plano de reabilitação ${ }^{20}$.

Interessante ressaltar que, enquanto a normativa minerária fala em "reabilitação", o restante das normas ambientais colacionados menciona o termo "recuperação" ou "restauração". Dessa forma, mostra-se também importante delimitar melhor os conceitos de tais atividades. Iniciando pelo conceito de "recuperação de áreas degradadas", a partir de seu objetivo previsto no Art. $3^{\circ}$ do Decreto n. 97.632/89, pode-se tentar defini-las:

\footnotetext{
${ }^{19}$ Estas particularidades não são exploradas neste trabalho. Entretanto, para esclarecimentos adicionais, sugere-se consultar o texto da NRM-21, que estabelece, por exemplo, que as áreas pesquisadas só deverão ser reabilitadas em caso de não aproveitamento futuro. Caso contrário, se a área pesquisa for integrada à futura área da mina, eventualmente será considerada uma área impactada ou minerada e consequentemente também reabilitada, porém em momento futuro.
}

${ }^{20}$ DEPARTAMENTO NACIONAL DE PRODUÇÃO MINERAL, 2001. 
Art. $3^{\circ}$ - A recuperação deverá ter por objetivo o retorno do sítio degradado a uma forma de utilização, de acordo com um plano preestabelecido para o uso do solo, visando a obtenção de uma estabilidade do meio ambiente. ${ }^{21}$

Dessa forma, é possível definir a recuperação de áreas degradadas, como a execução de atividades técnicas em uma área degradada, de forma a estabilizar os processos de degradação existentes a uma condição não degradada, que pode ser diferente de sua condição original, ou de maneira a retornar o local às condições próximas das existentes antes da intervenção, processo conhecido também como restauração, definições previstas na Lei n. 9.985/00, conforme já mencionado. Entre tais atividades, podem ser citadas: a revegetação, que é composta pela fixação localizada de espécies vegetais (herbáceas ou arbóreas), ou até reflorestamentos extensivos; atividades geotécnicas, de execução de obras de engenharia (com ou sem estruturas de contenção e retenção), incluindo obras hidráulicas, visando à estabilidade física; e remediação, através de métodos de tratamentos químicos ou biológicos para eliminar, neutralizar, imobilizar, confinar ou transformar elementos ou substâncias contaminantes, visando à estabilidade química do ambiente.

Já a reabilitação de área degradada seria explicitamente um projeto visando especificamente o seu aproveitamento para outra finalidade, ou seja, seu uso futuro. O uso futuro, conforme definido pela NRM-21, em 21.2.6, é entendido como a utilização prevista da área impactada pela atividade mineira levando-se em consideração suas aptidões e intenção de uso pós-operacional ${ }^{22}$.

Conforme já mencionado, pelas definições apresentadas é possível perceber que o termo "recuperação" é amplamente utilizado e de forma indiscriminada, podendo incorporar os sentidos de restauração e reabilitação. Tal ocorre pelo caráter assistemático da legislação ambiental, sobretudo aquela incidente sobre as atividades minerárias, uma vez que o ordenamento ambiental concorre com o ordenamento regulatório, emanado da entidade reguladora do setor mineral que, conforme já mencionado, também possui atribuições ambientais. Essas deficiências da legislação ambiental inclusive merecem o comento da doutrina ambiental:

${ }^{21}$ BRASIL, 1989.

${ }^{22}$ DNPM, 2001. 
Primeiramente, nesta visão crítica, o traço mais marcante da nossa legislação ambiental é seu perfil assistemático, gravíssimo pecado para um regime normativo que, pela sua abrangência e caráter transdisciplinar (interno e externo), não se mantém de pé sem um mínimo de organicidade e sistematicidade. No emaranho de normas existentes, difícil mesmo é encontrar matérias nas quais não existam conflitos normativos, em que os dispositivos, nos vários níveis legislativos, falem a mesma língua. Nada mais proveitoso para o degradador ambiental do que a existência de normas que se antagonizam, com isso deixando o terreno livre para o exercício de atividades altamente lesivas ao meio ambiente ${ }^{23}$.

O DNPM também editou a NRM-20 ou Norma Reguladora da Mineração n. 20, também aprovada pela Portaria DNPM 237, de 18 de outubro de 2001, e que dispõe sobre a Suspensão, Fechamento de Mina e Retomada das Operações Mineiras. A norma define como fechamento $a$ cessação definitiva das operações mineiras ${ }^{24}$ e exige a comunicação prévia ao Ministro de Estado de Minas e Energia, em requerimento justificado acompanhado de uma série de informações técnicas, sobretudo relacionadas às atividades de exploração mineral, tendo em vista a própria natureza e função regulatória do $\mathrm{DNPM}^{25}$.

Entretanto, ainda que timidamente, há menção a alguns aspectos ambientais, como programas e planos referentes aos sistemas de disposição e de contenção, ao solo, à atmosfera e aos recursos hídricos, bem como a definição dos impactos ambientais nas áreas de influência do empreendimento levando em consideração os meios físico, biótico e antrópico. Ainda mais limitadas são as referências aos aspectos sociais, que se limitam às medidas de segurança para impedir o acesso de pessoas estranhas às áreas perigosas e relatórios sobre condições de saúde ocupacional dos trabalhadores. Por fim, a norma menciona a necessidade de apresentação ao órgão da aptidão e intenção de uso futuro da área, sem estabelecer, entretanto, as diretrizes para a definição desse uso ou a necessidade de consultar a população afetada.

Logo, merece destaque uma norma de outro espírito, mais coadunada com os novos conceitos mencionados sobre Fechamento de Mina. Trata-se da Deliberação Normativa n. 127, de 27 de novembro de 2008,

\footnotetext{
${ }^{23}$ MILARÉ, 2005, p.143.

${ }^{24}$ DNPM, 2001.

${ }^{25}$ Ver 20.4.1 e suas alíneas.
} 
emitida pelo Conselho Estadual de Política Ambiental (COPAM) de Minas Gerais, órgão colegiado, com participação da sociedade civil, com atribuições de formular normas técnicas e estabelecer os padrões de proteção, conservação e melhoria do meio ambiente no Estado.

A Deliberação Normativa COPAM 127/08 estabelece diretrizes e procedimentos para avaliação ambiental da fase de fechamento de mina e passa a exigir efetivamente que as atividades minerárias desenvolvidas no Estado de Minas Gerais incluam no seu planejamento os projetos de reabilitação ambiental da área impactada, que deverão ser executados concomitantes com a lavra, ao longo de toda a vida útil do empreendimento. Dessa forma, nos termos da regulamentação em comento, o fechamento de mina passa a ser um processo integrado ao processo de licenciamento ambiental de um empreendimento minerário, um dos motivos pelos quais se considera que a norma em questão não encontra paralelo entre as normas federais sobre o tema e a regulamentação dos demais Estados da Federação.

Como mecanismo para garantir que o fechamento de mina seja efetivamente considerado e suas ações e informações estejam disponíveis para a fiscalização ambiental, a norma exige em seu Art. $4^{\circ}$ que os empreendimentos minerários em processo de revalidação da licença ambiental de operação incluam no Relatório de Avaliação do Desempenho Ambiental (RADA) a descrição de todas as ações, implantadas ou em andamento, visando à reabilitação da área impactada, conforme previsto nos estudos ambientais que subsidiaram a análise das fases anteriores do licenciamento, bem como aqueles indicados pelos órgãos ambientais após as etapas de licenciamento.

Além disso, a norma mineira exige que o empreendedor apresente, para aprovação pelo órgão ambiental responsável, num prazo de dois anos antes do fechamento da mina, um Plano Ambiental de Fechamento de Mina (PAFEM), contemplando no mínimo:

I - a reavaliação dos aspectos e impactos ambientais diagnosticados nos estudos que subsidiaram os processos de licenciamento do empreendimento, de modo a verificar a real extensão dos impactos e a eficácia das medidas mitigadoras e compensatórias executadas;

II - a síntese e avaliação dos projetos e ações socioambientais desenvolvidos visando à sustentabilidade da área de influência do empreendimento;

III - a avaliação dos impactos socioambientais após o fechamento da mina, incluindo os aspectos relacionados à recolocação de trabalhadores e propostas para o envolvi- 
mento da comunidade no processo;

IV - a definição das ações que serão executadas após o fechamento da mina visando à manutenção das condições de segurança da área minerada e das estruturas existentes, a continuidade da reabilitação ambiental, a definição de parâmetros e frequência para o monitoramento e a identificação de indicadores de qualidade ambiental adequados;

V - a apresentação de proposta de alternativas para uso futuro da área minerada, considerando os aspectos sociais, econômicos e ambientais da área de influência direta do empreendimento;

VI - o cronograma de implantação do plano, incluindo todas as etapas previstas, os processos de avaliação e revisão e a execução do monitoramento ambiental;

VII - estimativa de custos do fechamento da mina, em cada etapa ${ }^{26}$.

Esse Plano deverá ser apresentado segundo um Termo de Referência disponibilizado pelo órgão ambiental, e deverá ser elaborado por uma equipe multidisciplinar composta por profissionais legalmente habilitados, com a respectiva Anotação de Responsabilidade Técnica (ART) ou documento equivalente.

Além disso, a norma exige, em seu Art. 10, que o empreendedor atualize constantemente o referido plano no decorrer de sua execução, sendo o mesmo acompanhado pelo órgão ambiental por meio de fiscalizações e avaliação de relatórios de situação a serem apresentados pelo empreendedor, podendo até mesmo, em caso de não conformidade ou de situação de risco, o órgão ambiental solicitar a realização de auditoria técnica externa.

\subsection{Mecanismos de Participação}

Após analisadas as obrigações dos empreendedores no que se refere ao fechamento de mina, bem como as atribuições dos órgãos ambientais na fiscalização e acompanhamento desse processo, a seguir, passa-se a identificar e analisar a previsão na norma mineira sobre Fechamento de Mina, qual seja, a Deliberação Normativa COPAM 127/08, de dispositivos que considerem a variável social e os mecanismos de participação popular no processo.

O primeiro ponto a ser destacado é a elaboração, nos termos do Art. $5^{\circ}$ da norma, do Plano Ambiental de Fechamento de Mina (PAFEM).

${ }^{26}$ MINAS GERAIS, 2008 
Entre as diretrizes mínimas a serem consideradas no plano, o empreendedor deverá avaliar os impactos socioambientais após o fechamento da mina, incluindo os aspectos relacionados à recolocação de trabalhadores e propostas para o envolvimento da comunidade no processo ${ }^{27}$.

Assim, é possível verificar que o fechamento de mina deverá considerar aspectos relacionados ao trabalho, sobretudo dos empregados do empreendimento, que após o encerramento das atividades deverão buscar outras opções profissionais, sendo auxiliados nesse processo pelo empreendedor, que deverá prever as alternativas nesse sentido, propondo ações para a desmobilização de mão de obra.

Não só aspectos relacionados ao trabalho deverão estar previstos como também quaisquer outros impactos socioambientais decorrentes do encerramento das atividades, tais como: a redução das receitas das atividades econômicas total ou fortemente dependentes do projeto; a diminuição na arrecadação municipal, seja pela diminuição na arrecadação de tributos, seja pela suspensão da participação dos resultados da mineração; perda ou mudança da identidade local fortemente ligada à atividade extrativa mineral; dentre outros. Somado à caracterização dos potenciais impactos, o empreendedor deverá prever as medidas mitigadoras visando à minimização dos impactos sociais na comunidade diretamente afetada pelo empreendimento.

A partir do dispositivo em comento, o empreendedor também deverá apresentar propostas para o envolvimento da comunidade no processo, ou seja, prever, além das disposições legais já existentes, outras formas de participação dos cidadãos no processo de fechamento de mina, além de ações para esclarecimento das partes interessadas.

Outro aspecto a ser avaliado no Plano de Fechamento é a apresentação, pelo empreendedor, de proposta de alternativas para uso futuro da área minerada, considerando os aspectos sociais, econômicos e ambientais da área de influência direta do empreendimento ${ }^{28}$. Dessa forma, à semelhança das obrigações relacionadas ao Estudo de Impacto Ambiental, previstas na Resolução CONAMA 01/86 e que exigem a apresentação de alternativas tecnológicas e locacionais dos projetos, o empreendedor deverá apresentar alternativas de uso futuro da área, para aprovação do órgão ambiental. Tais alternativas devem visar a uma condição estável, produtiva

\footnotetext{
${ }^{27}$ MINAS GERAIS, 2008.

${ }^{28}$ MINAS GERAIS, 2008.
} 
e autossustentável das áreas considerando também as aptidões e anseios da região e da comunidade afetada.

Para avaliar as aptidões e anseios das partes interessadas que estarão envolvidas na gestão da área impactada pós-encerramento, durante a vida útil do empreendimento podem ser realizados projetos socioambientais, tais como Estudos de Percepção e Comportamento Socioambiental (EPCA), Programa de Educação Ambiental (PEA) e Plano de Informação Socioambiental (PISA), conforme previsto no Termo de Referência de Plano Ambiental de Fechamento de Mina (PAFEM) ${ }^{29}$.

Além dos estudos, outra forma de avaliar a percepção da comunidade acerca do projeto de encerramento de uma mina seria através da obrigação prevista no Art. $8^{\circ}$ da Deliberação Normativa ora em estudo:

\footnotetext{
Art. $8^{\circ}$ - Para os empreendimentos enquadrados nas classes 5 e 6 , segundo a Deliberação Normativa COPAM $n^{\circ} 74 / 2004$, num prazo de até 180 (cento e oitenta) dias após a apresentação do Plano Ambiental de Fechamento de Mina ao órgão ambiental estadual, o empreendedor deverá promover reunião pública no município onde se localiza o empreendimento, com o objetivo de apresentar o Pafem às partes interessadas, com ênfase nos aspectos ambientais e sociais correlatos ao fechamento da atividade, bem como nas propostas de uso futuro da área minerada, com o intuito de colher opiniões e sugestões da comunidade diretamente afetada ${ }^{30}$.
}

Essa obrigação prevê a realização de uma reunião pública para apresentação do plano em questão à comunidade, explicitando os impactos socioambientais decorrentes do encerramento e colhendo opiniões e sugestões sobre as medidas mitigadoras eventualmente apresentadas, bem como sobre as alternativas de uso futuro apresentado. Trata-se de um procedimento participativo de consulta pública acerca das decisões que serão tomadas por empreendedor e Poder Público, decorrentes do fechamento de um empreendimento minerário, como forma de avaliar a percepção e as demandas da comunidade acerca desse processo. Tal reunião teria natureza jurídica de um procedimento de consulta pública acerca de aspectos e impactos ambientais de um projeto, para solucionar dúvidas e recolher críticas e sugestões para subsidiar a tomada de decisão. $\mathrm{O} \S 1^{\circ}$ do Art. $8^{\circ}$ determina que a realização da reunião deva ser planejada conjuntamente

\footnotetext{
${ }^{29}$ MINAS GERAIS, 2009.

${ }^{30}$ MINAS GERAIS, 2008.
} 
entre empreendedor e órgão ambiental responsável de forma a garantir ampla divulgação às partes interessadas. Entretanto, não há dispositivos legais na norma que disponham sobre o procedimento para sua realização.

Tendo em vista se tratar de procedimento bastante similar às audiências públicas, os procedimentos para execução dessas audiências, descritos na legislação sobre o tema, também devem ser seguidos, naquilo que cabível, nas reuniões públicas para avaliação dos Planos de Fechamento de Mina, sobretudo os procedimentos descritos na Resolução CONAMA 09, de 3 de dezembro de 1987, e na Deliberação Normativa COPAM 12, de 13 de dezembro de 1994, garantindo-se o Princípio da Participação Comunitária e buscando conciliar as visões, os interesses e as aspirações da empresa, da comunidade hospedeira do empreendimento e dos órgãos reguladores.

Pelos dispositivos previstos na Deliberação Normativa COPAM $127 / 08$, percebe-se que, para o fechamento de mina, foi adotado procedimento similar ao previsto no licenciamento ambiental já regulamentado no âmbito do Estado de Minas Gerais. Sob o ponto de vista do acesso e participação da sociedade às decisões técnicas, destacam-se semelhanças nos mecanismos institucionais: a já mencionada participação direta através de processo de consulta pública e a deliberação por órgão colegiado representativo e aberto à participação da sociedade civil.

Sobre este último, no Estado de Minas Gerais, o Conselho Estadual de Política Ambiental (COPAM) é quem tem a atribuição para analisar, orientar e licenciar, por intermédio de suas Unidades Regionais Colegiadas, a implantação e a operação de atividade efetiva ou potencialmente poluidora ou degradadora do meio ambiente. Da mesma forma, conforme previsto na Deliberação Normativa COPAM 127/08 em seu Artigo 9º Plano Ambiental de Fechamento de Mina será submetido à análise técnica com emissão de parecer para apreciação da Unidade Regional Colegiada (URC) do COPAM competente.

Dessa forma, ambos os procedimentos são submetidos ao crivo de órgão colegiado, com representantes da sociedade civil, que podem, em tese, na análise dos procedimentos, manifestar suas opiniões, concordâncias e discordâncias, podendo, ainda, aprovar e rejeitar as propostas ou propor esclarecimentos e medidas de controle adicionais.

Logo, em que pese eventuais críticas à efetividade da participa- 
ção e a paridade de composição entre os diversos interesses ${ }^{31}$, a participação em órgãos colegiados é considerada pela doutrina uma conquista democrática da sociedade, que possibilitaria de maneira virtuosa a sensibilização e a mobilização da sociedade, bem como uma maior visibilidade das organizações socioambientais ${ }^{32}$. Dessa forma, os procedimentos de fechamento de minas licenciadas pelo Estado de Minas Gerais, nos termos da normativa estadual, deverão também passar por este processo, em tese, voltado à construção de consensos, a partir da identificação de pontos conflitantes, discussão e negociação.

\section{O FECHAMENTO DE MINA NO DIREITO COMPARADO}

Para avaliar as prescrições sobre fechamento de mina nos diversos países mineradores, considera-se a revisão da literatura internacional sobre o tema, realizada por Macdonald, McGuire e Weston (2006). O artigo denominado "Integrated Closure Planning Review - Literature Review" foi elaborado pelo Social Sustainability Services, por solicitação do International Council on Mining and Metals (ICMM), fórum sediado em Londres, na Inglaterra, que reúne 22 das maiores empresas de mineração do mundo e 34 associações de mineração nacionais e regionais de vários países. O objetivo principal do ICMM é aprimorar as formas como atuam as companhias do setor para aumentar o desempenho de desenvolvimento sustentável dessas companhias.

No texto em questão, a primeira observação se refere às preocupações iniciais das companhias mineradoras em iniciar o planejamento do fechamento das minas no início das operações. Os autores ressaltam que essa preocupação inicialmente estava mais relacionada aos custos e riscos legais, porém hoje os aspectos sociais do fechamento das minas têm encontrado maior reconhecimento, uma vez que as empresas mineradoras têm considerado suas relações com as comunidades tão importantes quanto o cumprimento dos requisitos legais. Nesse sentido, Hoskins, citada por Macdonald, McGuire e Weston ${ }^{33}$, afirma que muitas empresas começaram a discutir com a comunidade os impactos sociais do fechamento da mina antes mesmo de sua construção e operação, ressaltando ainda a importância das ferramentas de avaliação e impactos sociais.

\footnotetext{
$\overline{{ }^{31} \text { AGRA FILHO, 2010, p. } 354 .}$

${ }^{32}$ AGRA FILHO, 2010, p. 353.

${ }^{33}$ HOSKINS, citada por MACDONALD; MCGUIRE; WESTON, 2006.
} 
Sobre um diálogo trilateral entre as companhias mineradoras, a comunidade e os diversos níveis de governo, Macdonald, McGuire e Weston $^{34}$, analisando a obra de Paulo de Sá, afirmam que os projetos de mineração mais bem-sucedidos foram aqueles em que a companhia mineradora apoiou o crescimento da capacidade da comunidade local em prover a mina com bens e serviços até alcançar um padrão sustentável nesses negócios. Sobre esse aspecto, uma questão complicada é a de as mineradoras assumirem o papel governamental de prover serviços locais necessários, tais como hospitais e escolas, que podem ser sucateados após o encerramento das atividades minerárias, uma vez que esses serviços nunca foram de fato assumidos pela comunidade e governos locais, e estes não desenvolveram capacidade suficiente para gerir por si mesmos e de forma sustentável tais instituições ${ }^{35}$.

Abordando o tópico participação popular, Macdonald, McGuire e Weston ${ }^{36}$ comentam a obra de Philip Peck sobre o planejamento de fechamento de minas na Europa, sendo que este autor conclui que a melhor prática possível é o planejamento integrado do fechamento de mina - incluindo aspectos sociais, ambientais e econômicos -, garantindo que as comunidades sejam consultadas. Já Warhust e Noronha:

[...] dizem que envolver membros da comunidade local no escopo do EIA, identificando impactos e elaborando programas de reabilitação, assegura uma diminuição dos conflitos com as comunidades vizinhas à mina. Eles também apontam que, ao incluir a comunidade local, a empresa também garante que o plano elaborado para a área pós-mineração terá a aprovação da comunidade local ${ }^{37}$. (tradução nossa)

A literatura abordada por esses autores também advoga um processo participativo na definição do uso futuro das áreas, de forma que a comunidade possa avaliar esses usos, sendo que mais esforços deveriam ser colocados na coleta de opiniões da comunidade e na tentativa de alcançar

\footnotetext{
${ }^{34}$ MACDONALD; MCGUIRE; WESTON, 2006, p. 4.

${ }^{35}$ JACKSON, citado por MACDONALD; MCGUIRE; WESTON, 2006, p. 6.

${ }^{36}$ MACDONALD; MCGUIRE; WESTON, 2006, p. 4,5.

${ }^{37}$ They say that involving local community members in scoping for the EIA, identifying impacts and designing rehabilitation programs ensures a lessening of conflicts with the mine's neighbours. They also point out that, by including the local community, the company 'also ensures that the plan they arrive at for the post-mining land is one that has the approval of the local community'. (MACDONALD; MCGUIRE; WESTON, 2006, p. 5.)
} 
um verdadeiro consenso no uso final ${ }^{38}$.

Analisando a legislação e os regulamentos sobre o tema, Macdonald, McGuire e Weston ${ }^{39}$ analisaram os ordenamentos dos principais países mineradores, tais como Austrália, Canada, Índia, África do Sul e Estados Unidos, além das diretrizes do Banco Mundial e do International Finance Corporation (IFC). Em uma abordagem geral, afirmam:

A característica mais notável dos ordenamentos jurídicos analisados é a diversidade de mecanismos legais e requisitos que dizem respeito ao projeto/fechamento de mina. Embora muito poucos países e seus estados/províncias membros tenham aprovado regulamentos específicos de fechamento de minas, há uma tendência recente para o desenvolvimento e implementação de regulamentos e/ou orientações que se referem principalmente ao fechamento de mina. Estes documentos detalham os processos e conteúdo dos planos de fechamento de mina, além de esclarecer as funções e capacidade de efetivação das autoridades responsáveis ${ }^{40}$. (tradução nossa)

Na Índia, no documento denominado Guidelines for Preparation of Mine Closure Plan, que alterou o Regime de Concessão Mineral indiano (Mineral Concession Rules, 1960) e as regras de Conservação e Desenvolvimento Mineral (Mineral Conservation and Development Rules, 1988), não há previsões específicas para envolvimento de partes interessadas apesar da previsão de aspectos sociais, tais como previsões para trabalhadores demitidos e acompanhamento das repercussões nas expectativas da sociedade pelo fechamento de mina ${ }^{41}$.

Já na África do Sul, o Mineral and Petroleum Resources Development Act prevê a elaboração de um Plano de Fechamento de Mina como parte do Programa de Gestão Ambiental do empreendimento. Esse Plano possui um conteúdo mínimo descrito na norma, que quase não menciona requisitos de participação popular. O regulamento se limita a dispor que é um requisito necessário mencionar no referido plano o registro de partes

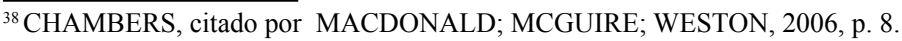

${ }^{39}$ MACDONALD; MCGUIRE; WESTON, 2006.

${ }^{40}$ The most notable feature of the legal frameworks reviewed is the diversity of legal mechanisms and requirements which pertain to project/mine closure. Although very few countries and their constituent states/provinces have enacted specific mine closure regulations, there is a recent trend towards the development and implementation of regulations and/or guidelines which relate primarily to mine closure. These documents detail the processes and contents of mine closure plans in addition to clarifying roles and enforcement capacity of the responsible authorities. (CHAMBERS, citado por MACDONALD, MCGUIRE E WESTON, 2006, p. 9.)

${ }^{41}$ ÍNDIA, 2003.
} 
interessadas e afetadas consultadas durante o processo ${ }^{42}$.

Por seu lado, a Austrália, em conjunto com a Nova Zelândia, desenvolveu diretrizes sobre fechamento no documento chamado Strategic Framework for Mine Closure ${ }^{43}$. Esse documento dispõe sobre os objetivos e princípios do fechamento de mina e é aplicável, porém não de forma obrigatória, para mineradoras australianas atuando dentro e fora da Austrália. As diretrizes de fechamento previstas possuem um capítulo inteiro sobre o envolvimento das partes interessadas, definindo inclusive os objetivos e princípios desse processo.

As instruções para o envolvimento de partes interessadas são bastante detalhadas e não encontram precedente nas demais normas e regulamentos analisados, envolvendo várias etapas, tais como: Identificação de Partes Interessadas, Consulta Efetiva, Estratégia de Comunicação Direcionada, Recursos Adequados e Trabalho com a Comunidade ${ }^{44}$.

Conforme a previsão australiana e neozelandesa, o processo de Consulta Efetiva deve começar durante a fase de planejamento e continuar até a fase de fechamento. A consulta não deve ser seletiva, mas deve envolver todas as partes interessadas no projeto e no uso futuro da área impactada. Outras partes interessadas, tais como ONGs, podem ter interesse no projeto e devem ser incluídas no processo de consulta. Para ser eficaz, a comunicação deverá envolver um processo de escuta e feedback, bem como de informação. Citando a EPA, agência de proteção ambiental americana, este regulamento dispõe que o processo de "consulta é sobre percepção e realidade $(E P A, 1995)$ e as percepções só podem ser aferidas através da escuta das partes afetadas e interessadas" (tradução nossa) ${ }^{45}$.

No Canadá, os governos provinciais são responsáveis por regulamentar a mineração em suas jurisdições. Nesse país, o governo nacional só tem jurisdição sobre os territórios federais e além-mar. Dessa forma, as Províncias de British Columbia, Manitoba, Alberta, Ontário, Terra Nova e Labrador possuem regulamentos que exigem a apresentação de um plano de recuperação no momento da solicitação de autorização para minerar, mas não especificam a inclusão de aspectos sociais nem o engajamento das

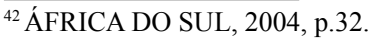

${ }^{43}$ AUSTRALIAN AND NEW ZEALAND MINERALS AND ENERGY COUNCIL, 2000.

${ }^{44}$ AUSTRALIAN AND NEW ZEALAND MINERALS AND ENERGY COUNCIL, 2000, p. VIII.

${ }^{45}$ Consultation is about both perception and reality (EPA, 1995), and perceptions can only be gauged by listening to the affected stakeholders and interested parties. (AUSTRALIAN AND NEW ZEALAND MINERALS AND ENERGY COUNCIL, 2000, p. 3.)
} 
partes interessadas ${ }^{46}$.

Nos Estados Unidos, por se tratar também de uma federação, os Estados detêm a mesma competência para regulamentar a mineração que as províncias canadenses. Por esse motivo, há uma grande variação na experiência de cada Estado, sendo que alguns já possuem, há mais de 20 anos, programas eficazes, com um razoável nível de recursos e experiências significativas. Por outro lado, há Estados com programas de fechamento recentes, ainda não totalmente institucionalizados.

Apesar disso, quase todos os estados dos EUA adotam conceitos básicos semelhantes incluindo o envolvimento das partes interessadas, embora alguns Estados tenham definições mais restritivas do que outros, sobre que tipo de pessoas constitui as partes interessadas com direito à participação. De todas as maneiras, a notificação pública é uma prática comum e "no geral os órgãos reguladores possuem um uma ampla definição de 'partes interessadas', resolvendo todas as dúvidas no sentido de permitir a participação” (tradução nossa) ${ }^{47}$.

Tendo analisado esses ordenamentos, Macdonald, McGuire e Weston concluem que as disposições legais sobre a participação de partes interessadas no processo de fechamento de mina ainda são inconsistentes, sendo as oportunidades para comentários da população extremamente limitadas, embora já seja prática comum nos Estudos de Impactos Ambientais $^{48}$.

\section{COMPARATIVO}

Comparando a normativa específica sobre fechamento de mina existente no ordenamento jurídico brasileiro, mais especificamente a norma mineira contida na Deliberação Normativa COPAM 127/08, com aquelas existentes em outros países com liderança global na atividade minerária, podem-se avaliar possíveis méritos da legislação nacional, bem como possibilidades de avanço.

Do ponto de vista da competência, tem-se que, no Brasil, assim como nos Estados Unidos e Canadá, as unidades federativas, no caso os

\footnotetext{
${ }^{46}$ MACDONALD; MCGUIRE; WESTON, 2006, p. 12,13.

${ }^{47}$ There is a practice of public notification, however, and 'in general, the agencies apply a very broad definition of 'interested parties', calling any doubts in favour of allowing participation. (DANIELSON, citado por MACDONALD; MCGUIRE; WESTON, 2006, p. 13.)

${ }^{48}$ MACDONALD; MCGUIRE; WESTON, 2006, p. 15.
} 
Estados brasileiros, têm competência para legislar sobre o fechamento de mina. Entretanto, essa competência decorre da competência concorrente para legislar sobre meio ambiente, prevista no Art. 24, VI, da Constituição da República de 1988, não possuindo os Estados brasileiros, diferentemente das unidades federativas americanas e canadenses, competência para legislar sobre recursos minerários, competência essa que no Brasil é privativa da União (Art. 22, XII da Constituição da República de 1988).

Apesar da possibilidade dos estados brasileiros regulamentarem o fechamento de mina, diferentemente da experiência americana, até o momento apenas o Estado de Minas Gerais, líder na produção minerária no país, possui legislação específica sobre o tema. Dessa forma, abre-se a possibilidade para outros Estados com tradição na atividade de exploração minerária, tais como Pará e Goiás, editarem normas sobre o tema, podendo inclusive trazer inovações ao quadro jurídico nacional.

Sob o aspecto histórico, a normativa específica brasileira é relativamente recente, possuindo pouco mais de 3 anos, enquanto a experiência internacional já acumula em alguns países mais de 10 anos, como é o caso de Austrália, Nova Zelândia e Estados Unidos. Curiosamente os países com normas mais recentes, Índia (2003) e África do Sul (2004), juntamente com o Brasil fazem parte do grupo de países em desenvolvimento. ${ }^{49}$

A norma de Minas Gerais dispõe sobre a avaliação de aspectos sociais no fechamento de minas, ainda que de forma genérica: na mitigação desses aspectos como um dos objetivos do fechamento (Art. $3^{\circ}, \mathrm{I}$ ); na consideração destes aspectos para definição do uso futuro da área impactada (Art. $5^{\circ}, \mathrm{V}$ ); e como um ponto a ser destacado na apresentação do Plano de Fechamento de Mina - PAFEM para a comunidade (Art. $8^{\circ}$ ). Em comparação com os ordenamentos analisados, a norma peca por não prever disposições específicas sobre esses aspectos, como, por exemplo, sobre demissão de empregados (Índia) e comércio e indústria local (Austrália). Considerando a técnica normativa adotada no Estado de Minas Gerais, poder-se-ia advogar que tais prescrições deveriam estar contidas no Termo de

\footnotetext{
${ }^{49}$ Além disso, em que pese a existência de norma legal sobre o tema, apenas mais recentemente foi identificado o julgamento do primeiro Plano de Fechamento de Mina (PAFEM), referente a empreendimento da Mineração Rio Pomba Cataguases Ltda. O julgamento de aprovação deste PAFEM pela Unidade Regional Colegiada da Zona da Mata mineira teve início em 26 de março de 2012, na 84a Reunião Ordinária da referida URC, e até o momento não foi identificada sua continuidade, visto que, por solicitação do Ministério Público de Minas Gerais, membro da referida URC, foi baixado em diligência para complementação de informações pelo empreendedor, visto que o teor do documento não atendia completamente as previsões legais da norma mineira e do Termo de Referência específico. (MINAS GERAIS, 2012)
} 


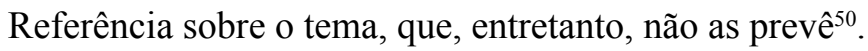

Acerca da participação da comunidade afetada, a norma mineira leva vantagem sobre alguns países analisados, tais como a Índia, que não trata sobre o assunto, e a África do Sul, que relega a questão ao arbítrio do empreendedor, este deve apenas informar no seu Plano de Fechamento quais as partes consultadas no processo de fechamento.

A previsão de uma reunião específica com a comunidade para apresentação e consulta acerca do Plano de Fechamento representa de certa forma um avanço da participação popular no processo de encerramento da atividade mineira. Entretanto, devem-se aguardar as futuras experiências para de fato afirmar que a legislação mineira estabeleceu mecanismos que propiciem a busca de um consenso nas decisões sobre o tema, especialmente no uso futuro da área impactada, como é a tônica em países como Austrália, Canadá e Estados Unidos.

Por fim, duas outras possibilidades de avanço da normativa brasileira, dignas de nota na comparação com os demais ordenamentos, são: (a) o estabelecimento de critérios para definir quem são as pessoas consideradas "partes interessadas", de maneira a explicitar de forma transparente e democrática os requisitos para participação no processo de fechamento, possibilitando às comunidades se capacitarem e engajarem de maneira efetiva nos processos e alijando pessoas estranhas às questões de fechamento, que eventualmente visem apenas tumultuar ou politizar o processo; e (b) elaboração de Termo de Referência mais detalhado, contendo metodologias e técnicas conhecidas, previsão de recursos, capacitação, dentre outros itens, a exemplo da normativa australiana, bem completa sobre o assunto.

\section{CONSIDERAÇÕES FINAIS}

De maneira geral, verificou-se que o licenciamento ambiental não foi suficiente para garantir a sustentabilidade no pós-mina, notadamente pelos aspectos socioeconômicos. Assim, é possível perceber a necessidade de novos ordenamentos jurídicos complementares para o fechamento de mina, que garantam o envolvimento das partes interessadas, inclusive na definição do uso futuro da área minerada, questão considerada importante pelos mais diversos países, em maior ou menor grau, sendo que a legislação a respeito ainda se encontra em franco incremento, sobretudo em

$\overline{{ }^{50} \text { MINAS GERAIS, } 2009 .}$ 
países em desenvolvimento com grande atividade minerária.

A maior parte das normas já existentes sobre esse tema ressalta a necessidade de previsão de aspectos sociais e mitigação de impactos no processo de fechamento, bem como do envolvimento das partes interessadas, assim entendidas como aquelas pessoas impactadas pelo empreendimento ou pelo seu fechamento ou, ainda, aquelas afetadas pelo uso futuro da área impactada.

No Brasil, apenas no Estado de Minas Gerais, verificaram-se avanços nesse sentido. Apesar das críticas tecidas à legislação de Minas Gerais sobre o tema, a norma é digna de importância, tendo em vista se tratar da primeira norma brasileira específica sobre o fechamento de mina e por estar alinhada com vários dos modernos princípios e procedimentos previstos na legislação mundial sobre o tema, dentre eles o mecanismo de consulta pública, muito embora as decisões finais sobre o fechamento não necessitem de aprovação das comunidades afetadas.

Tendo em vista a regulamentação recente, as práticas futuras e a aplicação efetiva do Plano de Fechamento de Mina, dentro dos critérios estabelecidos, darão os contornos à real importância da norma e ao acerto do Conselho Estadual de Política Ambiental de Minas Gerais (COPAM) em legislar a respeito. Por se tratar de órgão colegiado aberto à participação da sociedade civil mediante representação, é possível que as oportunidades de participação popular nos processos de fechamento de mina sejam ampliadas, no curso destes julgamentos ou até mesmo mediante a revisão da legislação em questão, podendo, inclusive, provocar a normalização em nível nacional pelo Conselho Nacional de Meio Ambiente (CONAMA).

\section{REFERÊNCIAS}

ÁFRICA DO SUL. R. 527. Mineral and Petroleum Resources Development Act (28/2002): Mineral and Petroleum Resources Development Regulations. Government Gazette Staatskoerant. 23 Abr. 2004. Disponível em: $\quad<$ http://www.petroleumagencysa.com/Libraries/Regulation/regula1. sflb.ashx>. Acesso em: 01 jul. 2012.

AGRA FILHO, Severino Soares. Os conflitos ambientais e os instrumentos da política nacional de meio ambiente. In: ZHOURI, Andréa; LASCHEFSKI, Klemens. (Orgs). Desenvolvimento e conflitos ambientais. Belo Horizonte: Editora UFMG, 2010, p. 351-359. 
AUSTRALIAN AND NEW ZEALAND MINERALS AND ENERGY COUNCIL (ANZMEC). Strategic Framework for Mine Closure. 2000. Disponível em: $<$ http://www.ret.gov.au/resources/Documents/mcmpr/Strategic_Framework_for_Mine_Closure.pdf $>$. Acesso em: 01 jul. 2012.

BRASIL. Constituição (1988). Constituição da Republica Federativa do Brasil. Disponível em: <http://www.planalto.gov.br/ccivil_03/Constituicao/Constituicao.htm>. Acesso em: 20 jun. 2012.

. Decreto n. 97.632, de 10 de abril de 1989. Dispõe sobre a regulamentação do Artigo

$2^{\circ}$, inciso VIII, da Lei n. 6.938, de 31 de agosto de 1981. Diário Oficial da União, Brasília, 12 abr. 1989. Disponível em: <http://www.planalto.gov. br/ccivil_03/decreto/19801989/D97632.htm>. Acesso em: 30 jun. 2012.

. Lei n. 6.938, de 31 de agosto de 1981. Dispõe sobre a Política Nacional do Meio Ambiente, seus fins e mecanismos de formulação e aplicação. Diário Oficial da União, Brasília, 02 set. 1981. Disponível em: <http://www.planalto.gov.br/ccivil_03/leis/16938.htm>. Acesso em: 20 jun. 2012.

. Lei n. 9.985, de 18 de julho de 2000. Regulamenta o art. 225, § 1o, incisos I, II, III e VII da Constituição Federal, institui o Sistema Nacional de Unidades de Conservação da Natureza e dá outras providências. Diário Oficial da União, Brasília, 19 jul. 2000. Disponível em: $<$ http://www. planalto.gov.br/ccivil_03/leis/L9985.htm>. Acesso em: 12 mar. 2013.

DEPARTAMENTO NACIONAL DE PRODUÇÃO MINERAL. Portaria 237 de 18 de outubro de 2001. Determinar a publicação das Normas Reguladoras de Mineração - NRM. Diário Oficial da União, Brasília, 19 out. 2001. Disponível em: <http://www.dnpmpe.gov.br/Legisla/Port_237_ 01.htm>. Acesso em: 20 jun. 2012.

FLORES, José Cruz do Carmo. Fechamento de Mina: aspectos técnicos, jurídicos e socioambientais. 2006. 309f. Tese (Doutorado) - Universidade Estadual de Campinas, Programa de Pós Graduação em Geociências, Campinas. Disponível em: <http://www.bibliotecadigital.unicamp.br/ document/?down=vtls000406634>. Acesso em: 30 jun. 2012.

FREIRE, William, Código de Mineração Anotado. Belo Horizonte: Man- 
damentos, 2010.

FREITAS, Vladimir Passos de; FREITAS, Gilberto Passos de. Crimes contra a Natureza. Belo Horizonte: Editora Revista dos Tribunais, 2001.

INDIA. Guidelines for Preparation of Mine Closure Plan. 10 abr. 2003. Disponível em: <http://ibm.nic.in/mineclosuregl.pdf > . Acesso em: 01 jul. 2012.

INTERNATIONAL COUNCIL ON MINING AND METALS. Planning for Integrated Mine Closure: Toolkit. Londres, 2008. Disponível em: $<$ http://www.icmm.com/ourwork/projects/mineclosure>. Acesso em: 30 jun. 2012.

MACDONALD, Catherine; MCGUIRE, Geraldine; WESTON, Helen. Integrated Closure Planning Review -Literature Review. Australia: Social Sustainability Services, 2006. Disponível em: $<$ http://www.icmm.com/document/285>. Acesso em: 30 jun. 2012.

MILARÉ, Edis. Direito do ambiente: doutrina, jurisprudência, glossário. 4. ed. São Paulo: Editora Revista dos Tribunais, 2005.

MINAS GERAIS. Ata da 84a Reunião Ordinária da Unidade Regional Colegiada Zona da Mata. Conselho Estadual de Política Ambiental - COPAM. 26 mar. 2012. Disponível em: <http://200.198.22.171/down. asp? $\mathrm{x}$ caminho=reunioes/sistema/arquivos/ata/\&x_nome $=$ Ata_\%EDntegra_84\%AA_reuni\%E3o.pdf>. Acesso em: 02 jul. 2012.

. Decreto n. 44.667, de 3 de dezembro de 2007. Dispõe sobre a reorganização do Conselho Estadual de Política Ambiental - COPAM, de que trata a Lei Delegada n. 178, de 29 de janeiro de 2007. Diário Oficial de Minas Gerais, Belo Horizonte, 04 dez. 2007. Disponível em: $<$ http:// www.siam.mg.gov.br/sla/download.pdf?idNorma=7551>. Acesso em: 01 jul. 2012.

. Deliberação Normativa COPAM 127, de 27 de Novembro de 2008. Estabelece diretrizes e procedimentos para avaliação ambiental da fase de fechamento de mina. Diário Oficial de Minas Gerais, Belo Horizonte, 29 nov. 2008. Disponível em: <http://www.siam.mg.gov.br/sla/download. pdf?idNorma=8732>. Acesso em: 20 jun. 2012. 
. Termo de Referência de Plano Ambiental de Fechamento de

Mina - PAFEM. Câmara Temática de Indústria, Mineração e Infraestrutura do Conselho Estadual de Política Ambiental - COPAM de Minas Gerais. Belo Horizonte, 29 set. 2009. Disponível em: <http://www.semad. mg.gov.br/images/stories/firmulariosregularizacao/novo2009/tr_pafem_a provado cim.doc>. Acesso em: 01 jul. 2012.

ORGANIZAÇÃO DAS NAÇÕES UNIDAS. Declaração do Rio sobre Meio Ambiente e Desenvolvimento. Rio de Janeiro, 1992. Disponível em: <http:/www.onu.org.br/rio20/img/2012/01/rio92.pdf>. Acesso em: 01 jul. 2012.

. The Future We Want. Rio de Janeiro, 2012. Disponível em: $<$ http://www.uncsd2012.org/content/documents/727The Future We Want 19 June 1230pm.pdf>. Acesso em: 02 jul. 2012.

POVEDA, Eliane Pereira Rodrigues. A eficácia legal na desativação de empreendimentos minerários. São Paulo: Signus Editora, 2007.

REGENSBURGER, Brigite; COMIN, Jucinei José; AUMOND, Juares José. Integração de técnicas de solo, plantas e animais para recuperação de áreas degradadas. Ciência Rural, Santa Maria, v. 38, n. 6, p.1773-1776, set. 2008 .

Recebido: 16/10/2013

Aceito: $26 / 11 / 2013$ 